\title{
Antibody Facilitation of Multiple Sclerosis-like Lesions in a Nonhuman Primate
}

\author{
Claude P. Genain, * My-Hoa Nguyen, * Norman L. Letvin, ${ }^{1}$ Rachel Pearl, * Richard L. Davis, ${ }^{*}$ Martin Adelman, ** \\ Marjorie B. Lees, ${ }^{5}$ Christopher Linington, ${ }^{\star \star}$ and Stephen L. Hauser ${ }^{\star}$ \\ ${ }^{*}$ Department of Neurology and ${ }^{\ddagger}$ Department of Pathology, University of California, San Francisco, California $94143 ;{ }^{8}$ E.K. Shriver \\ Center, Waltham, Massachusetts 02254; "Neurology Service, Massachusetts General Hospital, Boston, Massachusetts, 02114; 'Division \\ of Viral Pathogenesis, Beth Israel Hospital, Harvard Medical School, Boston, Massachusetts 02215; and **Department of \\ Neuroimmunology, Max Planck Institute for Psychiatry, Martinsried, Germany
}

\begin{abstract}
In the human disease multiple sclerosis (MS), the immune mechanisms responsible for selective destruction of central nervous system myelin are unknown. In the common marmoset Callithrix jacchus, a unique demyelinating form of experimental allergic encephalomyelitis resembling MS can be induced by immunization with whole myelin. Here we show that the MS-like lesion can be reproduced by immunization against the extracellular domain of a single myelin protein, myelin/oligodendrocyte glycoprotein (MOG). By contrast, immunization against the quantitatively major myelin proteins myelin basic protein or proteolipid protein results in inflammation but little or no demyelination. Furthermore, in the presence of encephalitogenic (e.g., diseaseinducing) $T$ cells, the fully demyelinated lesion is reconstructed by systemic administration of IgG purified from whole myelin-, or MOG-immunized animals, and equally by a monoclonal antibody against MOG, but not by control IgG. Encephalitogenic $T$ cells may contribute to the MSlike lesion through disruption of the blood brain barrier that permits access of demyelinating antibody into the nervous system. The identification of MOG as a major target antigen for autoimmune demyelination in a nonhuman primate should facilitate development of specific immunotherapies for human MS. (J. Clin. Invest. 1995. 96:2966-2974.) Key words: experimental allergic encephalomyelitis - common marmoset - myelin/oligodendrocyte glycoprotein • inflammation • demyelinating antibody
\end{abstract}

Address correspondence to Dr. C. Genain, Department of Neurology, S 258; University of California, San Francisco; San Francisco, CA 94143-0435. Phone: 415-502-5684; FAX: 415-476-5229; E-mail: claudeg@itsa.ucsf.edu

Received for publication 14 June 1995 and accepted in revised form 13 September 1995.

1. Abbreviations used in this paper: CNS, central nervous system; CSF, cerebrospinal fluid; EAE, experimental allergic encephalomyelitis; GFAP, glial fibrillary acidic protein; MBP, myelin basic protein; MOG, myelin/oligodendrocyte glycoprotein; MS, multiple sclerosis; PLP, proteolipid apoprotein; rMOG, recombinant MOG; WM, white matter.

J. Clin. Invest.

(C) The American Society for Clinical Investigation, Inc

0021-9738/95/12/2966/09 \$2.00

Volume 96, December 1995, 2966-2974

\section{Introduction}

Multiple sclerosis (MS) ${ }^{1}$ lesions are characterized by large, sharply demarcated areas of demyelination associated with macrophage infiltration, accumulations of perivascular and parenchymal T cells, and progressive astrocytic proliferation (gliosis) (1). Despite observations of cellular $(2,3)$ and humoral (4) immune reactivity to myelin autoantigens in some patients, and some similarity to the autoimmune disease model experimental allergic encephalomyelitis (EAE) (1), the etiology of MS remains unknown. In inbred rodents, antigens capable of inducing EAE by active immunization include the predominant myelin proteins myelin basic protein (MBP) and proteolipid apoprotein (PLP) $(5,6)$, the minor myelin protein myelin/oligodendrocyte glycoprotein (MOG) (7), and myelin lipids (8) or nonmyelin proteins of central nervous system (CNS) (9). Reconstitution and adoptive transfer experiments (10-12) have established a primary role for antigen-specific $T$ cells in EAE. Antibody participation has also been suggested by observations that intact B cell function is required for full expression of EAE (13), and that clinical signs are enhanced and demyelination occurs following the administration of demyelinating antibodies. These may be directed against gangliosides and galactocerebroside (14), myelin associated glycoprotein (15), or MOG (7). Pathologically, typical acute EAE differs substantially from MS in that prominent inflammation occurs in gray, white and meningeal structures and demyelination is scant or absent.

A primary demyelinating form of EAE occurs in the common marmoset $C$. jacchus after immunization with whole white matter (WM). Typically, a chronic, relapsing remitting clinical course is observed. Pathologically, the disorder is characterized by the early development of large, sharply demarcated areas of demyelination and gliosis reminiscent of MS plaques (16). C. jacchus marmosets are also notable for the presence of permanent and stable bone marrow chimerism between fraternal siblings, resulting from sharing of a common fetal blood supply between developing embryos in utero. In contrast to rodent EAE (10-12), adoptive transfer of MBP-reactive T cells in this primate species was not sufficient to reproduce the distinctive pathologic lesion observed following active immunization with WM (17). Thus the pathogenesis of the demyelinating phenotype was unknown. The present study was undertaken to identify the target antigen(s) and immune mechanisms responsible for the MS-like lesion in $C$ jacchus.

\section{Methods}

Antigens. human MBP and human PLP were purified as previously described $(18,19)$. The nonglycosylated recombinant fusion protein 


\begin{tabular}{|c|c|c|c|c|c|c|c|c|c|}
\hline \multirow[b]{2}{*}{ Antigen } & \multirow[b]{2}{*}{ Animal } & \multirow[b]{2}{*}{$\begin{array}{l}\text { EAE (day } \\
\text { of onset) }\end{array}$} & \multirow{2}{*}{$\begin{array}{c}\text { Duration } \\
\text { (days) } \\
\text { initial/relapse }\end{array}$} & \multirow[b]{2}{*}{$\begin{array}{l}\text { Maximum } \\
\text { grade* }\end{array}$} & \multirow[b]{2}{*}{$\begin{array}{c}\mathrm{CSF} \\
\left(\mathrm{WBC} / \mathrm{mm}^{3}\right)^{*}\end{array}$} & \multicolumn{3}{|c|}{ Pathology } & \multirow[b]{2}{*}{$\begin{array}{l}\text { Day of } \\
\text { death }\end{array}$} \\
\hline & & & & & & $\begin{array}{c}\text { Subpial } \\
\text { inflammation }\end{array}$ & $\begin{array}{l}\text { Perivascular } \\
\text { cuffing }\end{array}$ & $\begin{array}{l}\text { Demyelination } \\
\text { (plaques) }\end{array}$ & \\
\hline \multirow[t]{2}{*}{ HWM 100 mg } & $140-90$ & 17 & 7 & $4(24)$ & $220(24)$ & + & +++ & +++ & 24 \\
\hline & 139-90 & 25 & 7 & $3(32)$ & $580(32)$ & + & +++ & +++ & 32 \\
\hline MBP $1 \mathrm{mg}^{\ddagger}$ & $361-90$ & 17 & $14 / 2$ & $2(51)$ & $80(51)$ & + & 0 & 0 & 51 \\
\hline MBP $1 \mathrm{mg}^{\ddagger}$ & $362-90$ & 36 & $10 / 24$ & $2(80)$ & ND & 0 & 0 & 0 & 80 \\
\hline MBP $500 \mu \mathrm{g}$ & $567-92$ & 18 & 3 & $2(20)$ & $76(20)$ & + & 0 & 0 & 20 \\
\hline \multirow[t]{2}{*}{ aa $1-21^{\ddagger}$} & $36-91$ & - & - & 0 & ND & & ND & & \\
\hline & $37-91$ & - & - & 0 & ND & 0 & 0 & 0 & 51 \\
\hline \multirow[t]{2}{*}{ aa $82-103^{\ddagger}$} & $100-89$ & 36 & $10 / 27$ & 1 & ND & & ND & & \\
\hline & $407-89$ & 25 & $33 /-$ & 1 & ND & & ND & & \\
\hline \multirow[t]{2}{*}{ aa $153-174^{\ddagger}$} & $296-90$ & 18 & 29 & $2(47)$ & ND & + & 0 & 0 & 47 \\
\hline & $297-90$ & 17 & 30 & $1(46)$ & ND & 0 & 0 & 0 & 47 \\
\hline \multirow[t]{2}{*}{ PLP $100 \mu \mathrm{g}^{\ddagger}$} & $325-91$ & 21 & $42 / 91$ & $2(51)$ & $140(151)$ & 0 & 0 & 0 & 158 \\
\hline & 190-91 & 24 & $30 / 14$ & $2(100)$ & $60(87)$ & 0 & 0 & 0 & 100 \\
\hline PLP $200 \mu \mathrm{g}$ & $267-88$ & 9 & 3 & $2(12)$ & 180 (12) & 0 & 0 & 0 & 12 \\
\hline PLP $200 \mu \mathrm{g}^{\ddagger}$ & $124-93$ & 14 & $17 / 57$ & $2(28)$ & $180(103)$ & + & + & + & 103 \\
\hline PLP $200 \mu \mathrm{g}+$ MBP $250 \mu \mathrm{g}$ & $88-88$ & 17 & 10 & $3(27)$ & $220(27)$ & + & + & + & 27 \\
\hline \multirow[t]{3}{*}{ rMOG $100 \mu \mathrm{g}$} & $123-93$ & 16 & 2 & $2(16)$ & $140(16)$ & + & 0 & 0 & 17 \\
\hline & $126-93$ & 17 & 2 & $3(18)$ & $360(18)$ & + & +++ & +++ & 18 \\
\hline & $83-89$ & 14 & 54 & $4(68)$ & $120(16)$ & + & ++ & +++ & 68 \\
\hline \multirow{2}{*}{$\begin{array}{l}\text { PLP } 200 \mu \mathrm{g}+\mathrm{MBP} 250 \mu \mathrm{g}+ \\
\text { rMOG } 100 \mu \mathrm{g}\end{array}$} & & & & & & & & & \\
\hline & $109-90$ & 17 & 9 & $3(25)$ & $420(25)$ & + & +++ & +++ & 25 \\
\hline
\end{tabular}

* Number in parentheses refer to days afer the first immunization. ${ }^{\ddagger}$ Animals were rechallenged at days 46 after the first immunization. $N D$, not done.

MOG (rMOG) containing the extracellular domain of rat MOG (aa 1125) was prepared as described in (20). The sequence of the construct is extended for the amino acids (Met)-Arg-Gly-Ser at its $\mathbf{~ N H}_{2}$ terminus, and for Arg-Ser-Gln-Ser-(His) 6 at its $\mathrm{COOH}$ terminus. The purity of all antigen preparations was confirmed by SDS-PAGE/Coomassie blue staining. MBP, major $18.5-\mathrm{kD}$ band; PLP, 24 and $20-\mathrm{kD}$ bands; MOG, 14 and $28 \mathrm{kD}$ aggregate form. 20-mer overlapping peptides of MBP were derived from the sequence of human MBP, which differs from monkey MBP by 4 of 172 aminoacids (5). The MOG overlapping peptides were synthetized according to the published sequence of rat MOG (21)

Induction of EAE. Animals were immunized with the indicated amounts of myelin proteins (Table I) or $100 \mu \mathrm{g}$ MBP-peptides dissolved in $0.25 \mathrm{ml}$ phosphate-buffered saline and mixed with an equal volume of complete Freund's adjuvant supplemented with $3 \mathrm{mg} / \mathrm{ml}$ of $\mathrm{H} 37 \mathrm{Ra}$ killed mycobacterium. Three MBP peptides corresponding to regions of human MBP known to be encephalitogenic in $C$. jacchus (17) were tested (aa 1-21, aa 82-103, and aa 153-174). All animals received $10^{10}$ killed Bordetella pertussis organisms intravenously on the day of immunization and $48 \mathrm{~h}$ later. Animals were cared for in full accordance with institutional guidelines. Cerebrospinal fluid (CSF) was obtained by puncture of the cisterna magna. All procedures were performed under brief ketamine $(10 \mathrm{mg} / \mathrm{kg}$ i.m.) anesthesia. Animals were killed under ketamine anesthesia with a lethal dose of intravenous pentobarbital. Histopathological examinations were performed on formalin-fixed tissues. EAE was scored on a clinical scale of 1 to 5 by observers blinded to the study, and neuropathologic findings of inflammation and demyelination were graded according to a scale of 0 to $3+(16)$.

Immunocytochemistry. Antibodies used in this study: CD3, rabbit anti human pan T cell; CD20, monoclonal mouse anti human B cell; CD68, monoclonal anti human macrophage (all from Dako); glial fibrillary acidic protein (GFAP), clone G.A.5 (Boehringer Mannheim). The immunoperoxidase method with [3,30-diamino-benzidine] (Bio- genex) was used. Positive controls for marmoset tissues were obtained using formalin-fixed spleen and lymph node tissues from normal $C$. jacchus.

Immune reactivity to myelin antigens. $\mathrm{T}$ cell proliferative responses were measured using $2 \times 10^{5}$ freshly isolated PBMC plated in 96-well plates in $200 \mu \mathrm{l}$ of AIMV medium (GIBCO BRL, Gaithersburg, MD) with the following antigens: human WM $(0.1 \%$, wt/vol $), \operatorname{MBP}(50 \mu \mathrm{g} /$ $\mathrm{ml})$, PLP $(10 \mu \mathrm{g} / \mathrm{ml})$, or $\mathrm{rMOG}(10 \mu \mathrm{g} / \mathrm{ml})$. After $48 \mathrm{~h}$ incubation, $0.5 \mu \mathrm{Ci}\left[{ }^{3} \mathrm{H}\right]$ thymidine was added and the cells were harvested $18 \mathrm{~h}$ later. Stimulation indices were calculated as the ratios of ${ }^{3} \mathrm{H}$ incorporation in stimulated/unstimulated (medium alone) PBMC. Antibody responses were tested in serial dilutions of $C$. jacchus sera using a dotblot microfiltration apparatus with purified MBP ( $250 \mathrm{ng} / \mathrm{dot})$, PLP $(500 \mathrm{ng} / \mathrm{dot})$, and rMOG ( $500 \mathrm{ng} / \mathrm{dot})$ adsorbed on $0.45 \mu \mathrm{m}$ nitrocellulose membranes. Color development was achieved using anti-monkey IgG coupled to immunoperoxidase (Sigma Chemical Co., St. Louis, MO) at a dilution of $1 / 4,000$ and enhanced DAB substrate according to the manufacturer's instructions (Pierce, Rockford, IL). Fine specificity of anti-MOG antibodies were determined by ELISA in 96-well plates coated using $1 \mu \mathrm{g}$ of synthetic rat MOG-peptides per well, with $100 \mu \mathrm{l}$ of sera (1:200 dilution) and $100 \mu \mathrm{l}$ of peroxidase-conjugated antimonkey IgG (1:6,000; Sigma Chemical Co.). Plates were developed with [o-phenylenediamine]-peroxidase substrate and read at $490 \mathrm{~nm}$.

Adoptive transfer of autoantibodies. Native $C$. jacchus antibodies ( $\mathrm{IgG}$ ) were purified from plasma by affinity chromatography over protein A-agarose using the MAPS buffer system (Bio-Rad Laboratories, Richmond, CA) according to the manufacturer's instructions, and then dialyzed against phosphate buffered saline before injection. The murine monoclonal anti-MOG antibody 8.18.C5 was purified from ascites supernatants (22). Animals were immunized with native MBP (500 $\mu \mathrm{g})$ and, at the time when clinical signs of EAE, CSF pleocytosis and T cell reactivity to MBP appeared, $150 \mathrm{mg} / \mathrm{kg}$ of $C$. jacchus $\mathrm{IgG}$ or 25 $\mathrm{mg} / \mathrm{kg}$ of 8.18.C5 were administered by a single intravenous injection. 

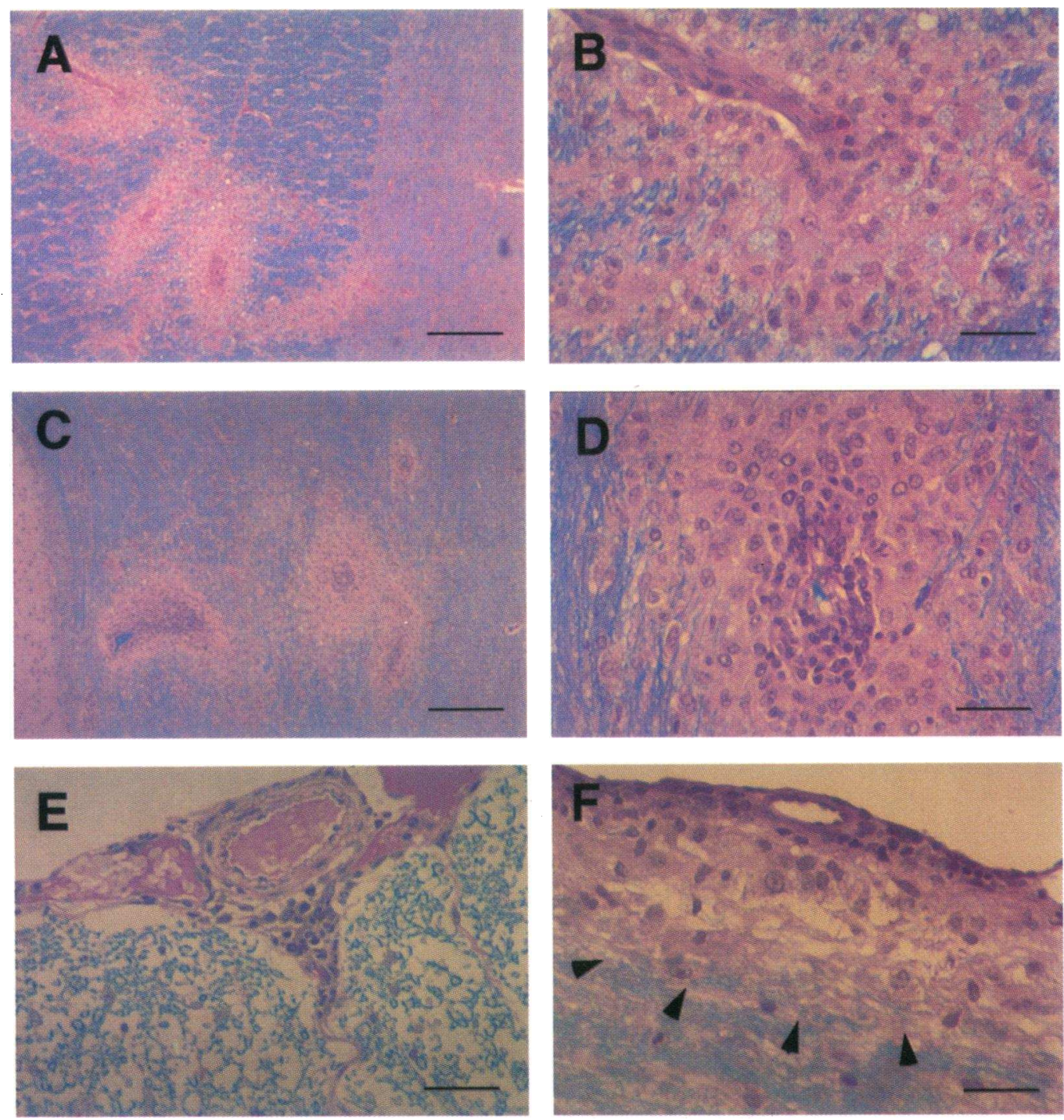

Figure 1. Representative pathologic findings of EAE in $C$. jacchus. Low $(A, C$, $G, I$, and $K)$ and high ( $B$, $D, E, F, H, J$, and $L$ ) power views of fields stained with hematoxylin/eosin $(G)$ or luxol fast blue/periodic acid Schiff. Bars, 200 and $40 \mu \mathrm{m}$, respectively. ( $A$ and $B$ ) Acute EAE induced by WM immunization. In $A$, foci of perivascular cuffing with pronounced demyelination. In $B$, higher magnification illustrates monocyte and macrophage infiltration; ( $C$ and $D$ ) EAE induced by rMOG. Note extensive perivascular cuffing with demyelination, and similar morphology of inflammatory cells as in WM-EAE; $(E)$ EAE induced by MBP. Note subpial infiltration by mononuclear cells in spinal cord, but absence of parenchymal infiltration or demyelination; $(F)$ in contrast, rMOG-induced EAE displayed prominent demyelination (arrowheads) underlying a subpial infiltrate in the spinal cord; $(G)$ MBP-induced EAE. Low power view of a subpial infiltrate (hematoxylin/eo$\sin ) ;(H)$ MBP-induced EAE. A perivascular inflammatory infiltrate in a dorsal peripheral root;

(I) PLP-induced EAE illustrating a single inflammatory infiltrate (arrows) in the brain stem. (animal 124-93). The arrowhead indicates the area shown at higher power in $J ;(J)$ note the incomplete perivascular demyelination (highlighted by the arrowheads); $(K$ and $L)$ MBP + PLP-induced EAE. Cervical spinal cord section illustrating an infiltrate in the lateral funiculus ( $K$, arrow), comprised of perivascular monocytes ( $L$, arrow) with accompanying areas of incomplete demyelination.

\section{Results}

To identify the role of different myelin proteins in $C$. jacchus EAE, groups of marmosets were actively immunized with either human WM, native MBP, synthetic peptides of MBP, PLP, or rMOG, either alone or in combination. All animals developed clinical signs of EAE within $36 \mathrm{~d}$ of immunization, with the exception of two animals immunized with a peptide corresponding to the amino acid sequence 1-21 of MBP (Table I). Severe clinical EAE (grades 3 and 4) and CSF pleocytosis indicative of CNS inflammation occurred solely in animals immunized with whole WM, rMOG alone or rMOG in combination with PLP and MBP. Immunization with either MBP or PLP resulted in mild clinical signs (grade 2) and a mild degree of CSF pleocytosis; immunization with synthetic peptides corresponding amino acid sequences $82-103$ or 153-176 of MBP also induced mild clinical disease, similar to that observed with whole MBP. After recovery from acute MBP or PLP induced
EAE, rechallenge with the same protein resulted in the development of new clinical signs but did not increase disease severity. Thus by clinical criteria, rMOG was a more potent autoantigen than either MBP or PLP in C. jacchus.

The characteristic pathology of EAE induced by immunization with whole WM was also reproduced by immunization with rMOG, but not with MBP or PLP. Two of three animals immunized with rMOG, and one animal immunized with rMOG in combination with MBP and PLP, developed intense CNS perivascular infiltration by mononuclear cells and macrophages accompanied by prominent concentric demyelination (Fig. 1). By contrast, with MBP immunization subpial inflammation was present but no demyelinating lesions could be identified. Inflammation in MBP-immunized animals was also present in spinal nerve roots (in particular the cauda equina), and it is possible that these inflammatory changes in the peripheral nervous system contributed to the clinical signs. These findings were identical to those previously reported to follow adoptive 

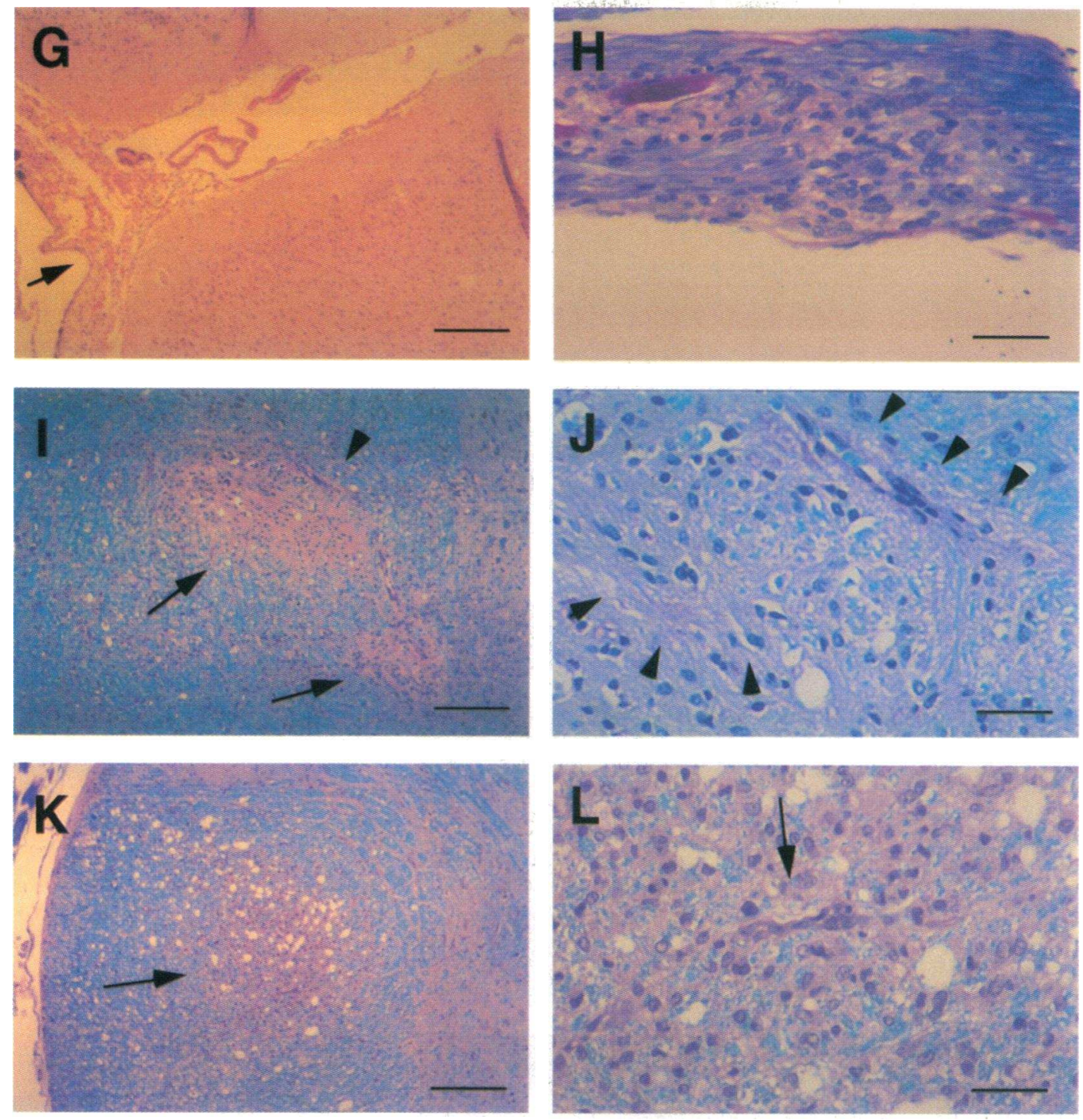

Figure 1 (Continued)

transfer of MBP-reactive T cell clones in this species (17). In PLP-immunized animals, subpial inflammation and occasional parenchymal perivascular mononuclear cell infiltrates occurred but demyelination was not present with the exception of a single focus in the brain stem of one of four PLP-immunized marmosets (Fig. 1, I-J). Immunization of another animal with a combination of PLP and MBP resulted in a more severe form of EAE than present with either antigen alone. In this animal, rare foci of perivascular cuffing, macrophage accumulation and incomplete demyelination were present in the spinal cord (Fig. $1, K-L)$. In both WM and rMOG EAE, acute inflammatory lesions were comprised predominantly of $\mathrm{T}$ cells located in perivascular cuffs and surrounding parenchyma (Fig. 2). Bcells were also present but in lower numbers than $\mathrm{T}$ cells. Marked astrocytic proliferation (gliosis) was also characteristic of both WM and rMOG EAE. Because no parenchymal inflammatory lesions were present in MBP-immunized animals, immunohistochemical studies in this model were confined to the characterization of the meningeal infiltrate. The meningitis in MBP-immunized animals consisted predominantly of CD3+ $\mathrm{T}$ cells (data not shown).

We examined circulating $\mathrm{T}$ cell and antibody responses in all immunized $C$. jacchus at the time of acute clinical disease. $\mathrm{T}$ cell proliferative responses could be readily detected against both MBP and rMOG but, consistent with earlier data (16), in no animal could a response to PLP be identified (Fig. $3 \mathrm{~A}$ ). Circulating antibodies against the immunizing protein developed in the MBP, PLP, and rMOG groups, and in WM-immunized animals antibodies against all three proteins were present (Fig. $3 B$ ). PLP-immunized animals developed, in addition to anti-PLP antibodies, antibodies to both MBP and rMOG. Only whole WM and rMOG produced demyelinating forms of EAE (Table I), thus the MS-like lesion appeared to require both a $T$ cell response to either MBP or MOG, and an antibody response against MOG. Overlapping synthetic peptides were used to map the fine specificity of the antibody response to rMOG. In each of three animals examined, this response was restricted to two regions of the protein spanning residues $1-25$ and 50-79 (Fig. $3 C)$.

To identify a role for pathogenic autoantibody in plaque formation, purified IgG antibodies were adoptively transferred to MBP-immunized recipients. As described above, immunization with MBP results in clinically mild EAE and no demyelination. IgG was prepared from the plasma of control animals 

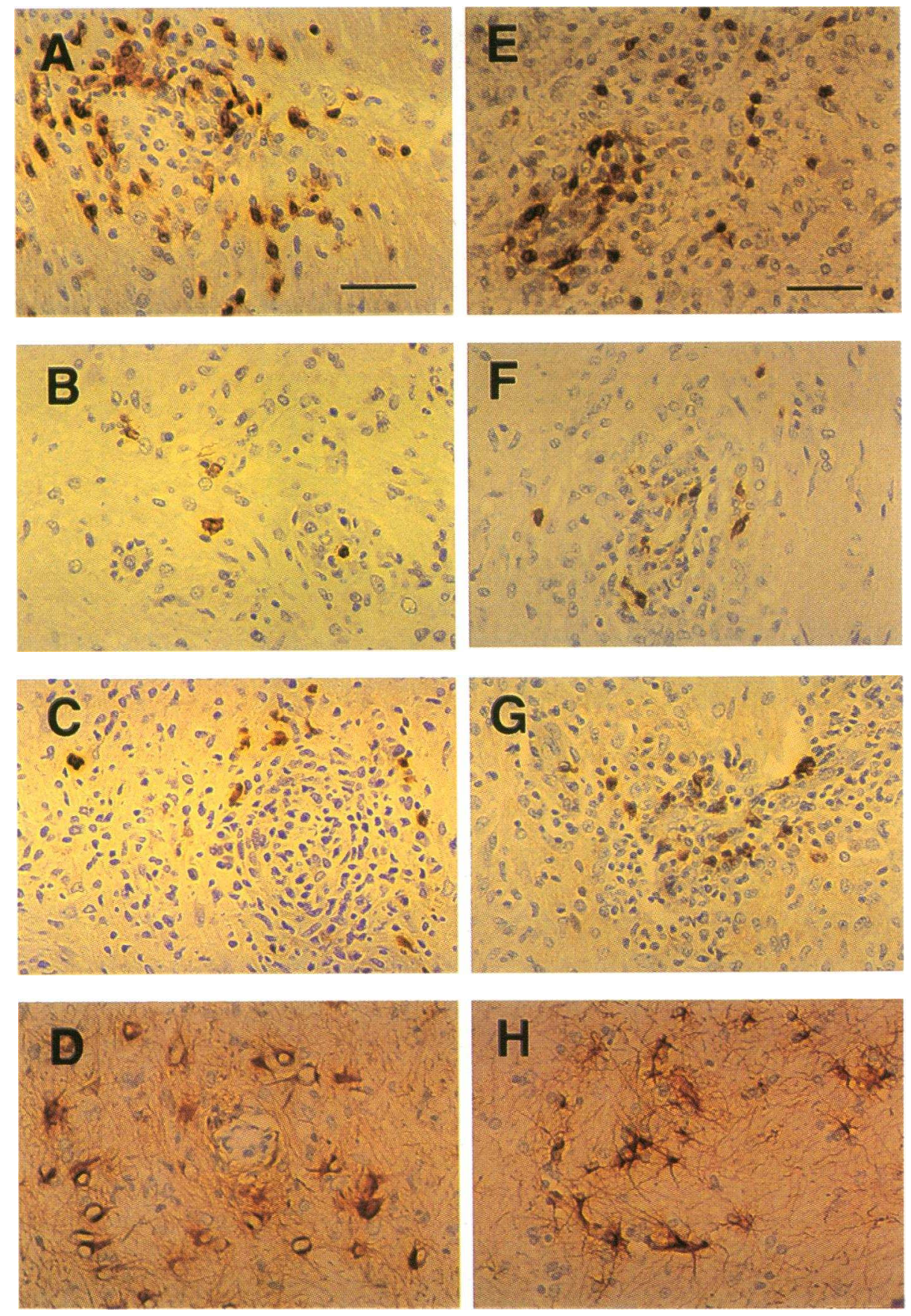

Figure 2. Immunocytochemistry of EAE lesions. $(A-D)$ WM-EAE and $(E-H)$ rMOG-EAE. $(A$ and $E$ ) CD3 + T cells constitute the majority of the perivascular infiltrates; some $T$ cells are noted to invade the parenchyma at a distance from the Virchow-Robin space. ( $B$ and $F$ ) $\mathrm{CD} 20+\mathrm{B}$ cells are present both in the perivascular space and parenchyma. ( $C$ and $G$ ) CD68+ macrophages, visible in areas of demyelination. ( $D$ and $H$ ) GFAP reactivity, illustrating intense peri-lesional gliosis. Bars, $40 \mu \mathrm{m}$.
(IgG-C) and also from animals with demyelinating forms of EAE induced by active immunization with either WM (IgGWM) or rMOG (IgG-rMOG). Adoptive transfer of IgG-WM, but not IgG-C, resulted in clinical deterioration within $48 \mathrm{~h}$ of antibody administration, and pronounced demyelination observed post-mortem (Table II). Clinical deterioration and demyelination also followed administration of either IgG-rMOG or the MOG-specific mouse monoclonal antibody 8.18.C5. Histologically, plaque formation in antibody recipients was indistinguishable from that resulting from active immunization with WM or rMOG (Fig. 4). No demyelination was present in marmosets immunized with complete Freund's adjuvant and Bordetella pertussis alone who then received monoclonal anti-MOG antibody, suggesting that demyelinating antibody requires an activated encephalitogenic $\mathrm{T}$ cell response to effectively target CNS myelin.

\section{Discussion}

This study establishes a primary role for MOG in an autoimmune MS-like illness in a primate. Although EAE was initially described in monkeys, the clinical course in primates tended to be hyperacute and the pathologic lesions hemorrhagic and necrotic rather than demyelinating in nature (23). With additional manipulations, for example steroid or other treatment administered during the acute period, chronic disease with demyelinating characteristics has been reported in primates $(24,25)$, but the models have been cumbersome to use and not pathologically 
A

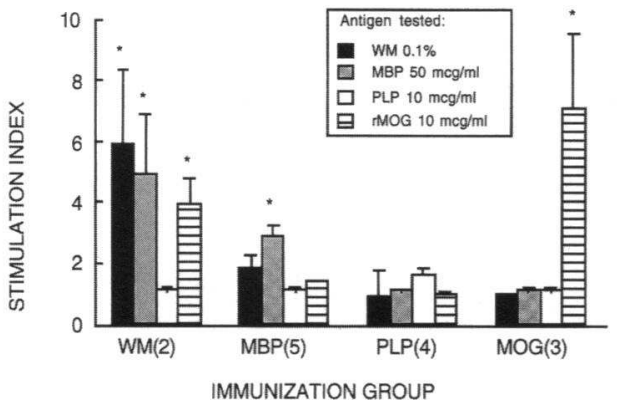

B

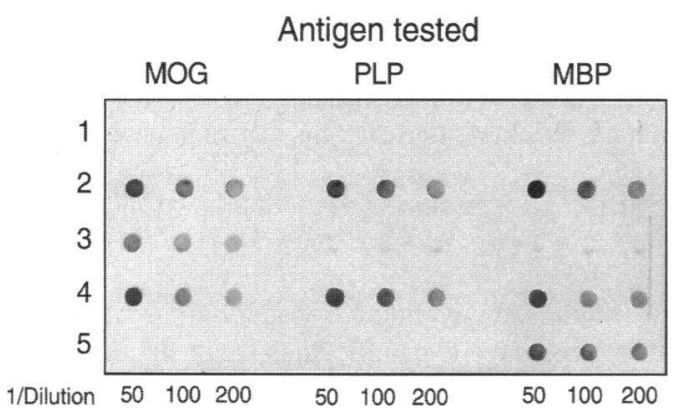

C

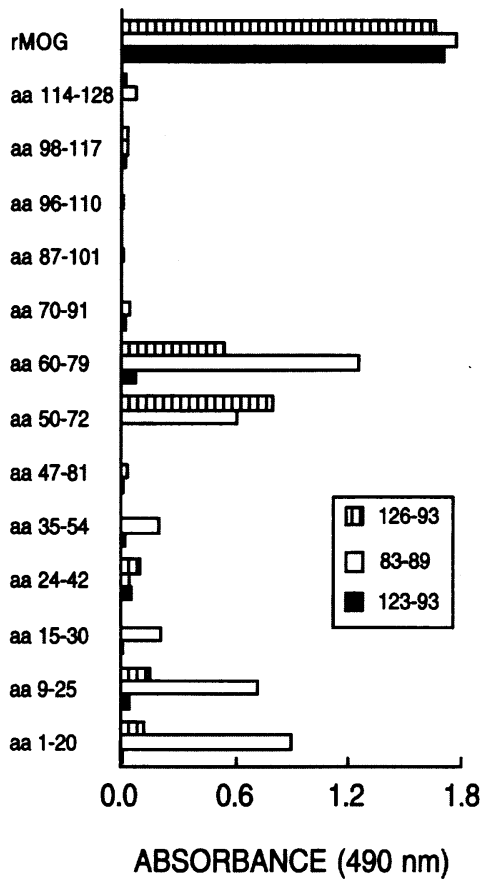

Figure 3. $\mathrm{T}$ cell and antibody responses to myelin antigens during C. jacchus EAE. (A) T cell proliferative responses against $W M$, MBP, PLP, and rMOG, measured as stimulation indices during acute EAE induced by different antigens. See Methods for details. For each immunization group the number of animals is shown in parentheses. $* P<0.05$ compared with control (no antigen), Student's $t$ test. ( $B$ ) Antibody responses to MBP, PLP and rMOG in animals immunized with the different antigens. Representative data for each immunization group are illustrated as follows: row 1 , control serum; row 2, WM; row 3, rMOG; row 4, PLP; row 5, MBP. ( $C$ ) Fine specificity of antiMOG antibody responses in rMOG-immunized animals determined by ELISA. In individual animals, reactivity was assessed by the use of overlapping peptides corresponding to the extracellular domain of MOG. As shown in the

top lane, all three immunized animals displayed antibodies against the whole rMOG protein. Two regions of MOG, located between aa 1-25 and aa 50-79, could be identified as antigenic targets of the antibody response. See methods for details of the assay.
MS-like. The unique EAE-WM lesion in C. jacchus, characterized by widespread acute demyelination, demonstrated that an MS-like phenotype indeed could be created in a species phylogenetically close to humans. The different EAE phenotypes that occur in $C$. jacchus using various immunization or adoptive transfer strategies permitted the identification of the mechanisms responsible for the fully developed lesion to be defined. In addition to the role of MOG as an autoantigen, current data also demonstrate the importance of autoantibodies in plaque formation. Synergism between an encephalitogenic $T$ cell response and specific demyelinating antibody appears to be required to produce the fully developed MS-like lesion. Both MBP and MOG appear to be effective $\mathrm{T}$ cell antigens in $C$. jacchus. Encephalitogenic T cells may function, at least in part, through disruption of the blood brain barrier and facilitation of entry of autoantibody into the CNS.

The precise mechanisms that underlie immune-mediated demyelination in EAE (or in MS) are not known. It has been postulated that, following entry of sensitized $T$ cells into the CNS, antigen recognition occurs in the context of antigen presentation by resident CNS cells (26). Inflammatory cytokines, including tumor necrosis factor- $\alpha$ and interferon- $\gamma$, are secreted and may directly injure oligodendrocytes, the myelin producing cells (27). Cytokine mediators are also likely to participate in recruitment of other inflammatory cells to the CNS for example macrophages, the cell type most often associated with demyelinating lesions. In EAE, a critical role for tumor necrosis factor- $\alpha$ in demyelination is suggested by the observation that rolipram, a

Table II. Adoptive Transfers of Autoantibodies in MBP-Immunized Marmosets

\begin{tabular}{|c|c|c|c|c|c|c|c|c|}
\hline Animal & $\begin{array}{c}\text { Onset of EAE } \\
\text { (days) }\end{array}$ & $\begin{array}{c}\mathrm{CSF} \\
\left(\mathrm{WBC} / \mathrm{mm}^{3}\right)\end{array}$ & Antibody (days pi) & $\begin{array}{c}\text { EAE grade } \\
\text { (before/after antibody) }\end{array}$ & $\begin{array}{c}\text { Subpial } \\
\text { inflammation }\end{array}$ & $\begin{array}{c}\text { Pathology } \\
\text { perivascular cuffing }\end{array}$ & $\begin{array}{l}\text { Demyelination } \\
\text { (plaques) }\end{array}$ & Day of death \\
\hline $120-92$ & 13 & 45 & IgG-WM (23) & $2 / 3$ & + & ++ & ++ & 37 \\
\hline $90-88$ & 21 & 70 & IgG-WM (23) & $2 / 3$ & + & ++ & ++ & 25 \\
\hline $91-88$ & 13 & 32 & 8.18.C5 (23) & $2 / 3$ & + & + & + & 37 \\
\hline $468-93$ & 19 & 140 & 8.18.C5 (34) & $2 / 3$ & + & ++ & ++ & 36 \\
\hline 499-93 & 9 & NA & IgG-rMOG(32) & $2 / 3$ & + & +++ & ++ & 41 \\
\hline $102-89$ & 26 & 52 & rIgG-C (28) & $2 / 2$ & + & 0 & 0 & 30 \\
\hline 119-92 & 41 & NA & IgG-C (41) & $2 / 2$ & + & 0 & 0 & 43 \\
\hline $102-93 *$ & - & 0 & 8.18.C5 (23) & $0 / 0$ & 0 & 0 & 0 & 25 \\
\hline $506-93 *$ & - & NA & 8.18.C5 (23) & $0 / 0$ & 0 & 0 & 0 & 25 \\
\hline
\end{tabular}

* Animals immunized with Freund's adjuvant and Bordetella pertussis only. $N A$, not available. 

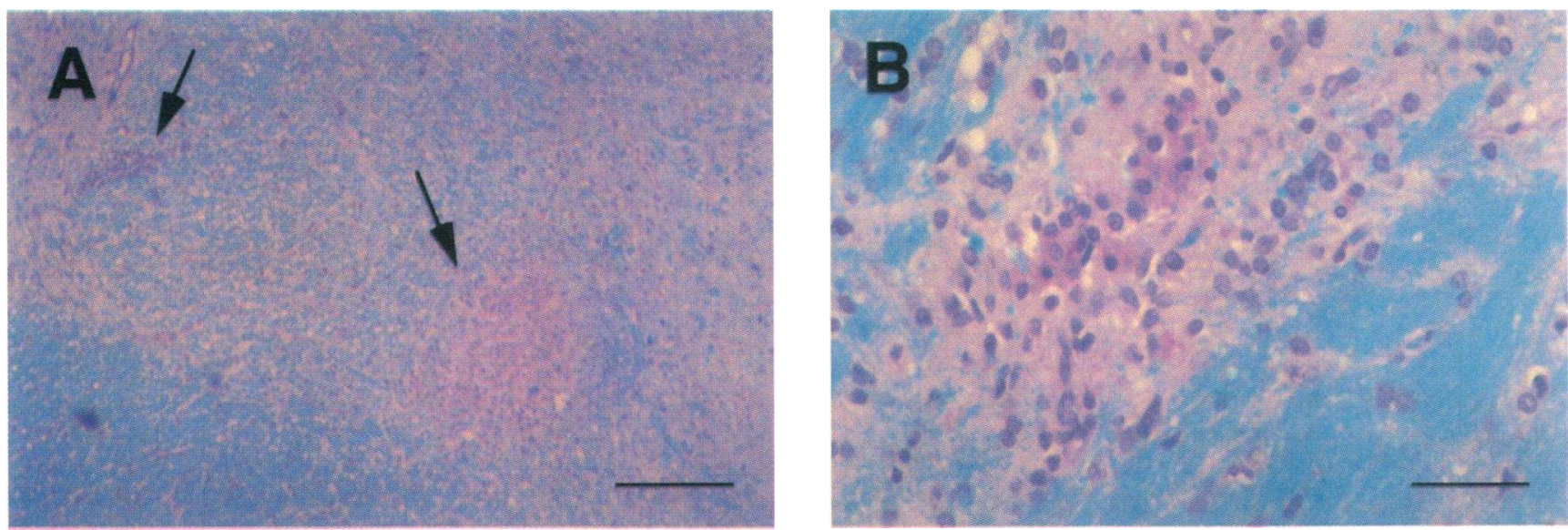

Figure 4. Adoptive transfer of demyelinating antibodies reproduces MS-like lesions in MBP-immunized $C$. jacchus. Typical lesions in the brain stem produced by intravenous administration of the monoclonal anti-MOG antibody 8.18.C5 $(A)$ or IgG-WM $(B)$, in animals previously immunized with MBP. Luxol fast blue/periodic acid Schiff. ( $A$ ) Low power view of parenchymal infiltrates (arrows). Bar, $200 \mu$ m. $(B)$ High power view of an infiltrate, demonstrating that demyelination has occurred. Bar, $40 \mu \mathrm{m}$.

selective inhibitor of the type IV phosphodiesterase, suppressed tumor necrosis factor $\alpha$ secretion, clinical disease manifestations, and demyelination $(28,29)$.

Earlier reports supported a role for antibody-mediated mechanisms in demyelination. In rodents, EAE can be converted from a nondemyelinating to a demyelinating form by administration of antimyelin antibodies. As in the current study, administration of demyelinating antibody was associated with a worsening of the clinical EAE score (7). Demyelinating activity of some autoantibodies correlated with their complement-fixing properties (30). In addition to direct complement-mediated tissue injury, antibodies might also facilitate demyelination via macrophage activation leading to cytokine-mediated injury to oligodendrocytes, myelin phagocytosis, or antibody dependent cell mediated cytotoxicity ( 31$)$.

In previous experiments, MOG was identified as a potentially important encephalitogen in rodents. A relapsing remitting form of EAE can be induced by a synthetic peptide corresponding to amino acid residues 92-106 of MOG in SJL mice (20). In contrast to rodents, the $C$. jacchus marmoset appears to be exquisitely sensitive to immunization with MOG relative to the more abundant myelin proteins, MBP and PLP. The strong proliferative response to MOG observed in WM-immunized $C$. jacchus is noteworthy given its low abundance $(\sim 0.1 \%$ of myelin proteins) in CNS. In the current study, the recombinant fusion protein rMOG was employed. This protein consists of the extracellular, immunoglobulin-like domain of rat MOG (21). Although the sequence of $C$. jacchus MOG is not known, the amino acid sequence of MOG is highly conserved between species. For example, human and rat MOG differ only by 12 amino acids within the immunoglobulin-like domain $(21,32)$. The importance of anti-MOG autoantibodies in demyelination might be due to the accessible localization of MOG, and in particular of the extracellular immunoglobulin-like domain of the molecule, at the outermost surface of the myelin sheath (33). In addition to anti-MOG IgG, other demyelinating autoantibodies may be present in IgG-WM that also contribute to the pathology in recipients of antibody transfers. Other potential autoantibodies notwithstanding, it is clear that anti-MOG IgG alone can facilitate demyelination in $C$. jacchus. In earlier in vivo or in vitro studies, demyelination was found to result from antibodies that recognized gangliosides, galactocerebroside (14) or myelin associated glycoprotein (15). Characterization of the repertoire of antigens that are targeted by pathogenic demyelinating antibodies in $C$. jacchus is in progress.

In PLP-immunized marmosets, circulating antibodies not only to PLP but also to MBP and MOG were detected. The PLP preparation used for immunization contained no detectable immunoreactivity against either MBP or rMOG (Fig. $3 B$, lines 3 and 5). Thus, it is unlikely that the PLP was contaminated with other myelin proteins. It is possible that the immune response to PLP resulted in production of antibody against one or several epitopes of PLP that were cross-reactive against other myelin proteins. More likely, antigenic spread due to secondary sensitization may explain the development of autoantibodies against MBP and MOG in PLP-immunized marmosets. This mechanism has been proposed to account for the expansion of antigenic spreading of encephalitogenic determinants during the course of disease in rodent models of EAE (34-36). It is of interest that little demyelination was present in PLP-immunized marmosets, despite the appearance of circulating antibodies reactive against rMOG. In these animals, there was no development of a proliferative T cell response against PLP, and with few exceptions perivascular cuffing in the CNS was lacking. Perhaps $\mathrm{T}$ cell activation in response to the dose of PLP used for immunization failed to disrupt the blood-brain barrier sufficiently to enhance passage of demyelinating antibody into the CNS. Alternatively, anti-MOG antibodies induced by PLP sensitization may be nonpathogenic. Some degree of demyelination was present in one marmoset immunized twice with PLP, and also in the animal immunized with a combination of MBP and PLP. This may indicate that PLP is effective at a higher dose, or that a synergism between MBP and PLP results in limited demyelination in $C$. jacchus.

Consistent with previous data (16) we did not detect a specific $T$ cell response against PLP in either WM-or PLPimmunized animals. In preliminary experiments and in earlier experience (16), proliferation assays were performed utilizing concentrations of PLP ranging from 0.5 to $40 \mu \mathrm{g} / \mathrm{ml}$ and in no case was a significant response detected. In addition, PBMC 
from PLP-immunized animals did not proliferate against PLPpeptide 139-151 which represent a major encephalitogenic determinant of PLP in SJL/J mice (37). It is thus unlikely that a PLP-specific $T$ cell response was present but not detected. In a different model of $C$. jacchus EAE in which a vaccinia-MBP construct was administered to modulate the disease course, proliferative responses to whole PLP were detected in some animals, indicating that the assay system was able to detect a response against this protein (C. Genain et al., manuscript in preparation). In the current study, high titers of anti-PLP antibodies were elicited in all PLP-immunized marmosets, raising the possibility that a Th2-like response to this protein occurs in this species.

Multiple lines of evidence support a role for antigen specific T cells reactive against MBP $(2), \operatorname{PLP}(38,39)$ and MOG (40) in the pathogenesis of MS. A primary T cell etiology to MS has been hypothesized based upon these studies, by analogy to MBP-induced EAE in rodents $(11,12)$, by other reports of T cell abnormalities in MS patients (41), and by demonstration of genetic linkage of MS to the major histocompatibility complex (MHC) (42) and T cell receptor beta chain loci (43). In the CSF of individuals with MS, evidence of an antibody-mediated immune response includes findings of elevated levels of immunoglobulin (44), membrane attack complexes indicating complement-mediated injury (45), and autoantibodies to myelin proteins (4). Using various in vitro systems, demyelinating antibody activity has been reported (46), and also disputed (47), in MS. Current findings raise the possibility that both a $\mathrm{T}$ cell and an antibody response may be required for the fully developed MS lesion or plaque to occur. In MS, perivenous inflammation and enhanced vascular permeability is not infrequently present in the retina, a tissue devoid of myelin (48). This implies that cellular infiltration and blood-brain barrier breakdown in MS does not result only from the effects of T cells that recognize antigens unique to myelin. By analogy to $C$. jacchus, the demyelinating phenotype in MS could result from autoantibodies directed against accessible myelin determinants in the context of a $\mathrm{T}$ cell response that enhances antibody access to the target tissue. Further definition of the role of autoantibodies directed against MOG, a minor but highly encephalitogenic protein, in plaque formation will be of considerable interest.

\section{Acknowledgments}

Brain tissue was provided by The Brain Tissue Resource Center, Belmont, MA, and Bordetella pertussis by Lederle Laboratories, Wayne, NJ. We are grateful to Prof. H. Lassmann and Prof. H. Wekerle for informative discussions.

This work was supported by National Institutes of Health, grants NS-30727 (S. L. Hauser) and NS-16945 (M. B. Lees). Dr. Genain was a post-doctoral fellow of the National Multiple Sclerosis Society.

\section{References}

1. Raine, C. S. 1983. Multiple sclerosis and chronic relapsing EAE: comparative ultrastructural neuropathology. In Multiple Sclerosis. Pathology, Diagnosis and Management. J. F. Hallpike, G. W. M. Adams, and W. W. Tourtellote, editors. William and Wilkins Co., Baltimore. 413-460.

2. Allegretta, M., J. A. Nicklas, S. Sriram, and R. J. Albertini. 1990. T cells responsive to myelin basic protein in patients with multiple sclerosis. Science (Wash. DC). 247:718-721.

3. Oksenberg, J. R., M. A. Panzara, A. B. Begovitch, D. Mitchell, H. A. Erlich, R. S. Murray, R. Shimonkevitz, M. Sherrity, J. Rothbard, C. C. A. Bernard, and L. Steinman. 1993. Selection for $\mathrm{T}$ cell receptor $\mathrm{V} \beta-\mathrm{D} \beta-\mathrm{J} \beta$ gene rearrangements with specificity for a myelin basic protein peptide in brain lesions of multiple sclerosis. Nature (Lond.). 362:68-70.

4. Panitch, H. S., C. J. Hooper, and K. P. Johnson. 1980. CSF antibody to myelin basic protein. Measurement in patients with multiple sclerosis and subacute sclerosing panencephalitis. Arch. Neurol. 37:206-209.

5. Tabira, T., and J. I. Kira. 1992. Strain and species differences of encephalitogenic determinants of myelin basic protein and proteolipid apoprotein. In Myelin: Biology and Chemistry. R. E. Martenson, editor. CRC Press, Inc., Boca Raton, FL. 783-799.

6. Tuohy, V. K. 1994. Peptide determinants of myelin proteolipid protein (PLP) in autoimmune demyelinating disease: a review. Neurochem. Res. 19:935944.

7. Schluesener, H. J., R. A. Sobel, C. Linington, and H. L. Weiner. 1987. A monoclonal antibody against a myelin oligodendrocyte glycoprotein induces relapses and demyelination in central nervous system autoimmune disease. J. Immunol. 139:4016-4021.

8. Moore, G. R. W., U. Traugott, M. Farooq, W. T. Norton, and C. S. Raine. 1984. Experimental autoimmune encephalomyelitis. Augmentation of demyelination by different myelin lipids. Lab. Invest. 51:416-424.

9. Kojima, K., T. Berger, H. Lassmann, D. Hinze-Selch, Y. Zhang, J. Gehrmann, K. Reske, H. Wekerle, and C. Linington. 1994. Experimental autoimmune panencephalitis and uveoretinitis transferred to the Lewis rat by $\mathrm{T}$ lymphocytes specific for the $\mathrm{S} 100 \beta$ molecule, a calcium binding protein of astroglia. J. Exp. Med. 180:817-829.

10. Paterson, P. Y. 1960. Transfer of allergic encephalomyelitis in rats by means of lymph node cells. J. Exp. Med. 111:119-135.

11. Pettinelli, C. B., and D. E. McFarlin. 1980. Adoptive transfer of experimental allergic encephalomyelitis in SJL/J mice after in vitro activation of lymph node cells by myelin basic protein: requirement for Lyt $1+2-\mathrm{T}$ lymphocytes. J. Immunol. 127:1420-1423.

12. Zamvil, S. S., D. J. Mitchell, A. C. Moore, K. Kitamura, L. Steinman, and J. B. Rothbard. 1986. T-cell epitope of the autoantigen myelin basic protein that induces encephalomyelitis. Nature (Lond.). 324:258-260.

13. Gausas, J., P. Y. Paterson, A. D. Day, and M. C. Dal Canto. 1892. Intact B-cell activity is essential for complete expression of experimental allergic encephalomyelitis in Lewis rats. Cell. Immunol. 72:360-366.

14. Roth, G. A., M. Roytta, R. K. Yu, C. S. Raine, and M. B. Bornstein. 1985. Antisera to different glycolipids induce myelin alterations in mouse spinal cord tissue cultures. Brain Res. 339:9-18.

15. Sergott, R. C., M. J. Brown, R. P. Lisak, and S. L. Miller. 1988. Antibody to myelin-associated glycoprotein produces central nervous system demyelination. Neurology. 38:422-426.

16. Massacesi, L., C. P. Genain, D. Lee-Parritz, N. L. Letvin, D. Canfield, and S. L. Hauser. 1995. Active and passively induced experimental autoimmune encephalomyelitis in common marmosets: a new model for multiple sclerosis. Ann. Neurol. 37:519-530.

17. Genain, C. P., D. Lee-Parritz, M. H. Nguyen, L. Massacesi, N. Joshi, R. Ferrante, K. Hoffman, M. Moseley, N. L. Letvin, and S. L. Hauser. 1994. In healthy primates, circulating autoreactive T cells mediate autoimmune disease. $J$. Clin. Invest. 94:1339-1345.

18. Deibler, G. E., R. E. Martenson, and M. W. Kies. 1972. Large scale preparation of myelin basic protein in central nervous tissue of several mammalian species. Prep. Biochem. 2:139-165.

19. Lees, M. B., and J. D. Sakura. 1979. Preparation of proteolipids. In Research Methods in Neurochemistry. N. Marks, and R. Rodnight, editors. Plenum Press, New York. 354-370.

20. Amor, S., N. Groome, C. Linington, M. M. Morris, K. Dornmair, M. V. Gardinier, J. M. Matthieu, and D. Baker. 1994. Identification of epitopes of myelin oligodendrocyte glycoprotein for the induction of experimental allergic encephalomyelitis in SJL and Biozzi AB/H mice. J. Immunol. 153:4349-4356.

21. Gardinier, M. V., P. Amiguet, C. Linington, and J. M. Matthieu. 1992. Myelin/oligodendrocyte glycoprotein is a unique member of the immunoglobulin superfamily. J. Neurosci. Res. 33:177-187.

22. Linington, C., B. Engelhardt, G. Kapocs, and H. Lassman. 1992. Induction of persistently demyelinated lesions in the rat following the repeated adoptive transfer of encephalitogenic T cells and demyelinating antibody. J. Neuroimmunol. 40:219-224.

23. Rivers, T. M., and F. F. Schwenther. 1935. Encephalomyelitis accompanied by myelin destruction experimentally produced in monkeys. J. Exp. Med. 61:689-702.

24. Shaw, C. M., E. C. Alvord, and S. Hornby. 1988. Chronic remittingrelapsing experimental allergic encephalomyelitis induced in monkeys with homologous myelin basic protein. Ann. Neurol. 24:738-748.

25. Massacesi, L., N. Joshi, D. Lee-Parritz, A. Rombos, N. L. Letvin, and S. L. Hauser. 1992. Experimental allergic encephalomyelitis in cynomolgus monkeys: quantitation of T-cell response. J. Clin. Invest. 90:399-404.

26. Hickey, W. F., B. L. Hsu, and H. Kimura. 1991. T-lymphocyte entry into the central nervous system. J. Neurosci. Res. 28:254-260. 
27. Benveniste, E. N. 1992. Inflammatory cytokines within the central nervous system: sources, function, and mechanism of action. Am. J. Physiol. 263:C1-C6.

28. Somner, N., P.-A. Loschmann, G. H. Northoff, M. Weller, A. Steinbrecher, J. P. Steinbach, R. Lichtenfels, R. Meyermann, A. Riethmuller, A. Fontana, J. Dichgans, and R. Martin. 1995. The antidepressant rolipram suppresses cytokine production and prevents autoimmune encephalomyelitis. Nature Med. 1:244-248.

29. Genain, C. P., T. Roberts, R. L. Davis, M. H. Nguyen, A. Uccelli, D. Faulds, Y. Li, J. Hedgpeth, and S. L. Hauser. 1995. Prevention of autoimmune demyelination in non human primates by a cAMP-specific phosphodiesterase inhibitor. Proc. Natl. Acad. Sci. USA. 92:3601-3605.

30. Piddlesden, S. J., H. Lassmann, F. Zimprich, B. P. Morgan, and C. Linington. 1993. The demyelinating potential of antibodies to myelin oligodendrocyte glycoprotein is related to their ability to fix complement. Am. J. Pathol. 143:555564 .

31. Piddlesden, S., H. Lassmann, I. Laffafian, B. P. Morgan, and C. Linington 1991. Antibody-mediated demyelination in experimental allergic encephalomyelitis is independent of complement membrane attack complex formation. Clin. Exp. Immunol. 83:245-250.

32. Pham-Dinh, D., B. Allinquant, M. Ruberg, B. Della-Gaspera, J. L. Nussbaum, and A. Dautigny. 1994. Characterization and expression of the cDNA coding for the human myelin/oligodendrocyte glycoprotein. J. Neurochem. 63:2353-2356.

33. Brunner, C., H. Lassmann, T. V. Waehneldt, J. M. Matthieu, and C. Linington. 1989. Differential ultrastructural localization of myelin basic protein, myelin/oligodendroglial glycoprotein, and $2^{\prime}, 3^{\prime}$-cyclic nucleotide phosphodiesterase in the CNS of adult rats. J. Neurochem. 52:296-304.

34. McCarron, R. M., R. J. Fallis, and D. E. McFarlin. 1990. Alterations in $T$ cell antigen specificity and class II restriction during the course of chronic relapsing experimental allergic encephalomyelitis. J. Neuroimmunol. 29:73-79.

35. Lehman, P. V., T. Forsthuber, A. Miller, and E. E. Sercarz. 1992. Spreading of $\mathrm{T}$ cell autoimmunity to cryptic determinants of an autoantigen. Nature (Lond.). 358:155-157.

36. Cross, A. H., V. K. Tuohy, and C. S. Raine. 1993. Development of reactivity to new myelin antigens during chronic relapsing autoimmune demyelination. Cell. Immunol. 146:261-269.

37. Tuohy, V. K., Z. Lu, R. A. Sobel, R. A. Laursen, and M. B. Lees. 1989.
Identification of an encephalitogenic determinant of myelin proteolipid protein for SJL mice. J. Immunol. 142:1523-1527.

38. Zhang, J., S. Markovic-Plese, B. Lacet, J. Raus, H. L. Weiner, and D. A Hafler. 1994. Increased frequency of interleukin 2-responsive $T$ cells specific for myelin basic protein and proteolipid protein in peripheral blood and cerebrospinal fluid of patients with multiple sclerosis. J. Exp. Med. 179:973-984.

39. Pelfrey, C. M., J. L. Trotter, L. R. Tranquill, and H. F. McFarland. 1994. Identification of a second $\mathrm{T}$ cell epitope of human proteolipid protein (residues 89-106) recognized by proliferative and cytolytic CD4+ $T$ cells from multiple sclerosis patients. J. Neuroimmunol. 53:153-161.

40. Kerlero de Rosbo, N., R. Milo, M. B. Lees, D. Burger, C. C. A. Bernard, and A. Ben-Nun. 1993. Reactivity to myelin antigens in multiple sclerosis. Peripheral blood lymphocytes respond predominantly to myelin oligodendrocyte glycoprotein. J. Clin. Invest. 92:2602-2608.

41. Hafler, D. A., M. Chofflon, E. Kurt-Jones, and H. L. Weiner. 1991. Interleukin-1 corrects the defective autologous mixed lymphocyte response in multiple sclerosis. Clin. Immunol. Immunopathol. 58:115-125.

42. Oksenberg, J. R., A. B. Begovitch, H. A. Erlich, and L. Steinman. 1993. Genetic factors in multiple sclerosis. JAMA. 270:2362-2369.

43. Seboun, E., M. A. Robinson, T. H. Doolittle, T. A. Ciulla, T. J. Kindt, and S. L. Hauser. 1989. A susceptibility locus for multiple sclerosis is linked to the T-cell receptor $\beta$ chain complex. Cell. 57:1095-1100.

44. Tourtelotte, W. W., A. R. Potvin, J. O. Fleming, K. N. Murthy, J. Levy, K. Syndulco, and J. H. Potvin. 1980. Multiple sclerosis: measurement and validation of central nervous system IgG synthesis rate. Neurology. 30:240-244.

45. Scolding, N. J., B. P. Morgan, W. A. J. Houston, C. Linington, A. K. Campbell, and D. A. S. Compston. 1989. Vesicular removal by oligodendrocytes of membrane attack complexes formed by activated complement. Nature (Lond.). 339:620-622.

46. Bornstein, M. B., and S. H. Appel. 1965. Tissue culture studies in demyelination. Ann. NY Acad. Sci. 122:280-286.

47. Grundke-Iqbal, I., and M. B. Bornstein. 1980. Multiple sclerosis: serum gamma globulins and demyelination in organ cultures. Neurology. 30:749-754.

48. Vine, A. K. 1992. Severe periphlebitis, peripheral retinal ischemia, and preretinal neovascularization in patients with multiple sclerosis. Am. J. Ophthalmol. 113:28-32. 